\title{
Giám sát của cơ quan dân cử trong tố tụng hình sự
}

\author{
Nguyễn Ngọc Chí ${ }^{1, *}$, Hà Thị Phương Bắc ${ }^{2}$ \\ Khoa Luật, Đại học Quốc gia Hà Nội, 144 Xuân Thủy, Cầu Gián, Hà Nội, Việt Nam \\ ${ }^{2}$ Uỷ ban Nhân dân huyện Hạ Hoà, Phú Thọ, Việt Nam \\ Nhận ngày 08 tháng 8 năm 2017 \\ Chỉnh sửa ngày 15 tháng 9 năm 2017; Chấp nhận đăng ngày 25 tháng 9 năm 2017
}

\begin{abstract}
Tóm tắt: Bộ luật tố tụng hình sự (BLTTHS) 2015 qui định nguyên tắc kiểm tra, giám sát trong tố tụng hình sự (TTHS) (Điều 33) đã hình thành nên cơ chế giám sát của cơ quan dân cử, đại biểu dân cử đối với hoạt động TTHS. Cơ chế giám sát này đã phát huy tích cực vai trò giám sát đối với hoạt động TTHS, đã hạn chế được sự lạm quyền trong hoạt động TTHS của các cơ quan có thẩm quyền, người có thẩm quyền tiến hành tố tụng, phát hiện vi phạm, kịp thời yêu cầu các cơ quan, tổ chức, cá nhân liên quan khắc phục. Tuy nhiên, thực tế hoạt động giám sát của cơ quan dân cử, đại biểu dân cử đối với hoạt động tố tụng hình sự còn nhiều bất cập, hạn chế làm cho chất lượng tố tụng chưa đạt được hiệu quả như mong muốn; quyền con người, quyền công dân còn bị xâm phạm, lợi ích nhà nước và trật tự pháp luật chưa được bảo đảm, công lý chưa được tôn trọng, đòi hỏi phải được khắc phục. Bài viết tập trung rõ các yêu cầu và kiến nghị khắc phục hạn chể hoạt động giám sát của cơ quan dân cử, đại biểu dân cử trong tố tụng hình sự.
\end{abstract}

Từ khóa: Giám sát, quốc hội, hội đồng nhân dân, tố tụng hình sự, Cơ quan dân cử, Đại biểu dân cử.

1. Xu hướng lạm quyền trong việc thực hiện quyền lực nhà nước mang tính tất yếu, do đó, và để hạn chế, khắc phục các quốc gia thường đặt ra cơ chế kiểm soát quyền lực. Cách thức được nhiều quốc gia sử dụng là cơ chế đối trọng, kiểm soát giữa các quyền lập pháp, hành pháp và tư pháp. Do vậy, hoạt động tư pháp, trong đó có hoạt động TTHS được đặt trong mối quan hệ đối trọng, kiểm soát đó và hướng tới việc giải quyết quyết vụ án khách quan, công bằng, công khai, dân chủ bảo đảm quyền con người và trật tự pháp luật. "Trong Nhà nước pháp quyền, các cơ quan quyền lực nhà nước không chỉ phải hoạt động trong khuôn khổ

\footnotetext{
*Tác giả liên hệ. ĐT.: 84-903408336.

Email: nguyenngocchi57@gmail.com

https://doi.org/10.25073/2588-1167/vnuls.4111
}

pháp luật mà còn bị giới hạn bởi pháp luật. Pháp luật không chỉ là cái mà các cơ quan quyền lực nhà nước phải tuân thủ mà còn là phương tiện để hạn chế chính quyền. Do đó, Nhà nước pháp quyền là Nhà nước mà quyền lực của nó được giới hạn để tránh việc xâm phạm các quyền và tự do của công dân" [1]. Chính vì vậy, ở đa phần các nước "giám sát của Nghị viện thường chỉ tập trung vào giám sát của chính phủ (nhánh quyền lực hành pháp); không giám sát tư pháp, nguyên thủ quốc gia, chính quyền địa phương...” [2]. Nghị viện không giám sát tư pháp, do Tòa án là cơ đại diện cho nhánh quyền tư pháp trong thế chân kiềng, kiềm chế, đối trợg với lập pháp và hành pháp, là tấm khiên cuối cùng để bảo vệ quyền và các tự do cơ bản của người dân; mặt khác tòa án còn có chức năng xét xử cả lập pháp và hành 
pháp nên "chức năng giám sát của Nghị viện không thể bao gồm giám sát tư pháp" [3].

Ở nước ta quyền lực nhà nước là thống nhất trên cơ sở phân công, kiểm soát giữa lập pháp, hành pháp và tư pháp, nên trách nhiệm giám sát hoạt động tư pháp nói chung và hoạt động TTHS nói riêng được đặt ra cho cơ quan dân cử, đại biểu dân cử, trong đó vai trò đặc biệt quan trọng thuộc về Quốc hội - Cơ quan quyền lực nhà nước cao nhất. "Quyền lực không được kiểm tra, giám sát, kiểm soát chặt chẽ sẽ bị tha hóa, lạm quyền đi ngược lại mong muốn và lợi ích của nhân dân" [4]. Trên tinh thần đó, Luật tổ chức Quốc hội, Luật tổ chức chính quyền địa phương, BLTTHS 2015... qui định chức năng, nhiệm vụ, quyền hạn và trách nhiệm giám sát tư pháp trong tố tụng hình sự. Những qui định này đã hình thành nên cơ chế giám sát của cơ quan dân cử, đại biểu dân cử đối với hoạt động TTHS, phát huy tích cực vai trò giám sát đối với hoạt động TTHS, đã hạn chế được sự lạm quyền trong hoạt động TTHS của các cơ quan có thẩm quyền, người có thẩm quyền tiến hành tố tụng; phát hiện vi phạm, kịp thời yêu cầu các cơ quan, tổ chức, cá nhân liên quan khắc phục. Thông qua giám sát của cơ quan dân cử, đại biểu dân cử, quyền con người, quyền công dân được bảo đảm; lợi ích của nhà nước và trật tự pháp luật được tôn trọng; hạn chế oan sai và bỏ lọt tội phạm trong tố tụng hình sự. "Hoạt động tố tụng hình sự không chỉ tác động mạnh mẽ đến cá nhân người phạm tội mà còn đối với cả xã hội, nhằm giữ gìn an ninh, trật tự xã hội, bảo đảm pháp chế, duy trì công lý. Do vậy, hoạt động tố tụng càng phải chịu sự kiểm tra, cơ chế giám sát khác nhau (cơ chế tự kiểm tra bên trong của mỗi hệ thống và cơ chế kiểm soát bên ngoài hệ thống) để bảo đảm cho các cơ quan có thẩm quyền tố tụng thực hiện đúng pháp luật; bảo đảm các vụ án được giải quyết chính xác, khách quan; bảo đảm tôn trọng các quyền con người trong các thủ tục tố tụng được pháp luật qui định" [5].

2. Điều 33 BLTTHS 2015 qui định nguyên tắc kiểm tra, giám sát trong tố tụng hình sự, làm định hướng cho kiểm soát quyền lực tư pháp, theo đó mọi hoạt động TTHS của Cơ quan có thẩm quyền THTT, người có thẩm quyền THTT đều phải đặt dưới sự kiểm tra, giám sát của mọi cơ quan, tổ chức, xã hội. Nguyên tắc này qui định thiết chế kiểm tra và thiết chế giám sát; Thiết chế kiểm tra được áp dụng cho Cơ quan có thẩm quyền THTT, người có thẩm quyền THTT như qui định của Khoản 1, Điều 33: "Cơ quan, người có thẩm quyền tiến hành tố tụng phải thường xuyên kiểm tra việc tiến hành các hoạt động tố tụng thuộc thẩm quyền; thực hiện kiểm soát giữa các cơ quan trong việc tiểp nhận, giải quyết nguồn tin về tội phạm, khởi tố, điều tra, truy tố, xét xử, thi hành án”. Như vậy, kiểm tra là hình thức kiểm soát nội tại (kiểm soát trong) của các cơ quan, người có thẩm quyền tiến hành tố tụng; các cơ quan, người có thẩm quyền tiến hành tố tụng có trách nhiệm kiểm tra tính hợp pháp, hợp lý, tính đúng đắn của mọi hoạt động tố tụng thuộc trách nhiệm quản lý, thuộc thẩm quyền của mình. Đồng thời các cơ quan có thẩm quyền tiến hành tố tụng còn có trách nhiệm kiểm soát lẫn nhau trong suốt quá trình tố tụng giải quyết vụ án. Giám sát là hình thức kiểm soát ngoài, là thẩm quyền của cơ quan, tổ chức không thuộc hệ thống cơ quan có thẩm quyền tiến hành tố tụng (cơ quan tiến hành tố tụng và cơ quan được giao nhiệm vụ tiến hành một số hoạt động điều tra), đó là: "Cơ quan nhà nước, Ủy ban Mặt trận Tổ quốc Việt Nam và các tổ chức thành viên của Mặt trận, đại biểu dân cử có quyền giám sát hoạt động của cơ quan, người có thẩm quyền tiến hành tố tụng; giám sát việc giải quyết khiếu nại, tố cáo của cơ quan, người có thẩm quyền tiến hành tố tụng.” (Khoản 2, Điều 33 BLTTHS 2015). Theo qui này thì chủ thể giám sát trong TTHS là các cơ quan nhà nước, tổ chức chính trị - xã hội mà đại diện là Ủy ban Mặt trận Tồ quốc Việt Nam và các tổ chức thành viên của Mặt trận, đại biểu dân cử trong việc giám sát hoạt động của các cơ quan, người có thẩm quyền tiến hành tố tụng; giám sát việc giải quyết khiếu nại, tố cáo trong TTHS. Điều 33 BLTTHS 2015 không qui định cơ quan dân cử (Quốc hội, Hội đồng nhân dân các cấp) là chủ thể giám sát đối với hoạt động TTHS, nhưng Hiến pháp 2013 qui định Quốc hội có quyền "giám sát tối cao 
đối với hoạt động của Nhà nước" (Điều 69) trong đó có hoạt động của cơ quan có thẩm quyền tiến hành tố tụng. Tinh thần này của Hiến pháp đã được thể chế hóa trong Luật tổ chức Quốc Hội, Luật tổ chức chính quyền địa phương. Điều 6 Luật tổ chức Quốc hội năm 2014 qui định: "1. Quốc hội giám sát tối cao việc tuân theo Hiến pháp, luật và nghị quyết của Quốc hội. 2. Quốc hội giám sát tối cao hoạt động của Chủ tịch nước, Ủy ban thường vụ Quốc hội, Chính phủ, Tòa án nhân dân tối cao, Viện kiểm sát nhân dân tối cao, Hội đồng bầu cử quốc gia, Kiểm toán nhà nước và cơ quan khác do Quốc hội thành lập". Hoặc Luật tổ chức chính quyền địa phương 2015, Điều 19, Khoản 8 qui định: "Giám sát việc tuân theo Hiến pháp và pháp luật ở địa phương, việc thực hiện nghị quyết của Hội đồng nhân dân tỉnh; giám sát hoạt động của Thường trực Hội đồng nhân dân, Ủy ban nhân dân, Tòa án nhân dân, Viện kiểm sát nhân dân cùng cấp, Ban của Hội đồng nhân dân cấp mình; giám sát văn bản quy phạm pháp luật của Ủy ban nhân dân cùng cấp và văn bản của Hội đồng nhân dân cấp huyện.”. Như vậy, việc không qui định trong BLTTHS 2015, cơ quan dân cử là chủ thể giám sát đối với hoạt động TTHS là một khiếm khuyết, chẳng những không thể hiện được vai trò quan trọng của cơ quan dân cử đối với việc kiểm soát hoạt động tư pháp trong lĩnh vực hình sự mà còn tạo ra sự không đồng bộ của hệ thống pháp luật nhà nước ta, làm giảm tính hiệu quả của cơ quan dân cử, đặc biệt là Quốc hội, cơ quan quyền lực nhà nước cao nhất.

Khi giám sát, các chủ thể giám sát "nếu phát hiện hành vi trái pháp luật của cơ quan, người có thẩm quyền tiến hành tố tụng thì cơ quan nhà nước, đại biểu dân cử có quyền yêu cầu, Ủy ban Mặt trận Tổ quốc Việt Nam và các tổ chức thành viên của Mặt trận có quyền kiến nghị với cơ quan có thẩm quyền tiến hành tố tụng xem xét, giải quyết theo quy định của Bộ luật này. Cơ quan có thẩm quyền tiến hành tổ tụng phải xem xét, giải quyết và trả lời kiến nghị, yêu cầu đó theo quy định của pháp luật." (Khoản 2, Điều 33 BLTTHS).
Những phân tích trên cho thấy, giám sát của cơ quan dân cử, đại biểu dân cử đối với hoạt động tố tụng hình sự có những đặc điểm sau: i) Giám sát hoạt động tố tụng hình sự của cơ quan dân cử, đại biểu dân cử nhằm mục đích bảo đảm tuân thủ pháp luật nghiêm chỉnh, đúng đắn trong toàn bộ quá trình tố tụng giải quyết vụ án hình sự của các cơ quan có thẩm quyền tiến hành tố tụng, người có thẩm quyền tiến hành tố tụng góp phần "bảo đảm cho quyền lực được vận hành đúng đắn và hiệu quả." [6]; ii) Quốc hội, Hội đồng nhân dân và đại biểu dân cử (Đại biểu Quốc hội, Đại biểu Hội đồng nhân dân) là một trong những chủ thể giám sát đối với hoạt động TTHS. Chủ thể giám sát này, khác với các chủ thể giám sát khác ở chỗ đây là giám sát mang tính chất quyền lực nhà nước chứ không phải là giám sát xã hội đối với hoạt động TTHS như Mặt trận Tổ Quốc; đồng thời đây là giám sát tối cao (của Quốc hội) chứ không phải là giám sát thông thường của các cơ quan nhà nước khác; iii) Đối tuợng giám sát của Cơ quan dân cử, đại biểu dân cử là tất cả các hoạt động tố tụng hình sự của các cơ quan có thẩm quyền tiến hành tố tụng, người có thẩm quyền tiến hành tố tụng, cũng như việc giải quyết khiếu nại, tố cáo. Hoạt động tố tụng giải quyết vụ án khá phức tạp, với nhiều thành phần tham gia (Cơ quan có thẩm quyền THTT; Người có thẩm quyền THTT; Người tham gia tố tụng), ảnh hưởng tới quyền con người, quyền công dân và các quyền khác; tác động tới quyền, lợi ích hợp pháp của nhà nước, của xã hội. Do đó, đối tượng giám sát này có tính đặc thù cao thể hiện ở chủ thể của đối tượng giám sát, ở hoạt động của đối tượng giám sát; iv) Hình thức và phuoong pháp giám sát: Mỗi chủ thể giám sát có các hình thức giám sát và phương pháp giám sát đặc thù xuất phát từ chức năng, nhiệm vụ của chủ thể giám sát. Cơ quan dân cử và đại biểu dân cử là cơ quan quyền lực trong hệ thống cơ quan nhà nước ta, có chức năng, nhiệm vụ, quyền hạn do Hiến pháp và các luật tổ chức qui định, có đối tượng giám sát được qui định trong BLTTHS 2015 nên luật qui định các hình thức và phương pháp giám sát hoạt động tố tụng hình sự phù hợp cho chủ thể giám sát này. Luật 
Tổ chức Quốc hội và Luật Tổ chức chính quyền địa phương ấn định các hình thức và phương pháp giám sát sau: Thư nhất, Quốc hội và Hội đồng nhân dân xem xét báo cáo công tác của TAND, VKSND trong giải quyết vụ án hình sự; Thư hai, Quốc Hội, Hội đồng nhân dân xem xét chất vấn và trả lời chất vấn tại kỳ họp Quốc hội và Hội đồng nhân dân; Thứ $b a$, Quốc hội xem xét đề nghị giám sát, xử lý văn bản trái pháp luật của TANDTC, VKSNDTC; Thư tur, Quốc hội bỏ phiếu tín nhiệm đối với Chánh án TANDTC, Viện trưởng VKSNDTC; Thú năm, các hình thức thực hiện quyền giám sát của Quốc hội và Hội đồng nhân dân đối với TAND, VKSND trong hoạt động tố tụng hình sự giữa hai kỳ họp, như: UBTVQH xem xét báo cáo, tò̀ trình của TANDTC và VKSNDTC; UBTVQH xem xét đề nghị giám sát, xử lý văn bản trái pháp luật của TANDTC, VKSNDTC; UBTVQH xem xét việc trả lời chất vấn của Chánh án TANDTC, VKSNDTC; Ủy ban pháp luật Quốc hội (UBPLQH) giám sát đối với TANDTC, VKSNDTC thuộc phạm vi quyền hạn, nhiệm vụ của Ủy ban...; Thứ sáu, hệ quả giám sát của cơ quan dân cử, đại biểu dân cử đối với hoạt động TTHS. Khi phát hiện vi phạm trong hoạt động TTHS, đại biểu dân cử đưa ra các yêu cầu, kiến nghị đối với cơ quan, người có thẩm quyền tiến hành tố tụng và những chủ thể này có trách nhiệm giải quyết các yêu cầu, kiến nghị đó theo qui định của pháp luật.

3. Giám sát của cơ quan dân cử, đại biểu dân cử đối với hoạt động TTHS có vai trò, ý quan trọng đối với quá trình tố tụng giải quyết vụ án. Vai trò, ý nghĩa đó thể hiện trên những khía cạnh sau:

i) Giám sát của cơ quan dân cử, đại biểu dân cử đối với hoạt động tố tụng hình sự nhằm bảo đảm cho Cơ quan dân cử, Đại biểu dân cử thực sự là đại diện cho ý chí, nguyện vọng và quyền làm chủ của nhân dân, tất cả quyền lực nhà nước thuộc về nhân dân trong lĩnh vực tư pháp hình sự. Hiến pháp 2013 khẳng định: Tất cả quyền lực nhà nước thuộc về nhân dân (khoản 2 Điều 2) và nhân dân thực hiện quyền lực của mình thông qua cơ quan đại diện là Quốc hội, Hội đồng nhân dân các cấp. Những cơ quan này thay mặt nhân dân thực thi quyền lực nhà nước trong các lĩnh vực lập pháp, hành pháp và tư pháp trên cơ sở và trong phạm vi Hiến pháp, pháp Luật. Các Nghị quyết của Quốc hội, Hội đồng nhân dân vừa mang tính đại diện, vừa mang tính quyền lực nhà nước, có giá trị bắt buộc chung cho mọi cơ quan, tổ chức và công dân ở cả nước. Do vậy, việc giám sát của các cơ quan dân cử, đại biểu dân cử đối với hoạt động tố tụng hình sự của Cơ quan có thẩm quyền THTT và Người có thẩm quyền THTT là tất yếu trong việc bảo đảm quyền lực nhà nước thuộc về nhân dân. Chính vì vậy, ngay từ khi bắt đầu công cuộc đổi mới, Văn kiện Đại hội đại biểu toàn quốc lần thứ VI của Đảng đã khẳng định: "Tăng cường hiệu lực quản lý của Nhà nước, trước hết nêu cao vị trí của Quốc hội và Hội đồng nhà nước, vai trò của HĐND các cấp" [7].

ii) Giám sát của các cơ quan dân cử, đại biểu dân cử đối với hoạt động tố tụng hình sự có vai trò quan trọng trong việc tăng cường hiệu lực, hiệu quả hoạt động tố tụng hình sự góp phần bảo đảm công lý, bảo vệ quyền con người, không làm oan người vô tội, không để lọt tội phạm. Thực tiễn đã chỉ ra, khi nào pháp chế xã hội chủ nghĩa trong hoạt động tố tụng hình sự được bảo đảm, các chủ thể TTHS tuân thủ tự giác, triệt để thì bộ máy nhà nước mới phát huy được sức mạnh vốn có để thực hiện chức năng, nhiệm vụ trong đấu tranh, xử lý tội phạm, bảo đảm công lý, bảo vệ quyền con người, hạn chế oan sai và bỏ lọt tội phạm. Do đó, giám sát của cơ quan dân cử, đại biểu dân có vai trò đặc biệt quan trọng trong việc tăng cường hiệu lực, hiệu quả của hoạt động tố tụng hình sự.

Giám sát của các cơ quan dân cử, đại biểu dân cử đối với hoạt động tố tụng hình sự là một trong những phương diện đảm bảo cho mọi hoạt động tố tụng hình sự được đảm bảo chính xác, khách quan, kịp thời. Thông qua hoạt động giám sát, Cơ quan dân cử, Đại biểu dân cử kịp thời phát hiện vi phạm trong quá trình hoạt động tố tụng giải quyết vụ án của Cơ quan có thẩm quyền THTT và Người có thẩm quyền THTT, yêu cầu họ khắc phục, đòi hỏi họ phải tiến hành tố tụng trên cơ sở pháp luật, tuân thủ 
nghiêm chỉnh pháp luật, từ đó mà Hiến pháp, pháp luật được tôn trọng và chấp hành nghiêm chỉnh trong quá trình tố tụng. Do đó, hoạt động giám sát của cơ quan dân cử, đại biểu dân cử đã góp phần quan trọng vào việc nâng cao hiệu quả của hoạt động tố tụng hình sự. Đồng thời, phát hiện, khắc phục vi phạm; hạn chế việc để lọt tội phạm và làm oan người vô tội trong quá trình giải quyết vụ án, góp phần bảo đảm công lý, bảo vệ quyền con người, quyền công dân.

iii) Giám sát của Cơ quan dân cử, Đại biểu dân cử đối với hoạt động tố tụng hình sự có vai trò quan trọng trong việc bảo đảm phát hiện hạn chế yếu kém của các chủ thể TTHS, xây dựng các cơ quan tư pháp trong TTHS trong sạch vững mạnh. Thông qua hoạt động giám sát Cơ quan dân cử phát hiện kịp thời những yếu kém, khiếm khuyết trong hoạt động tố tụng hình sự của Cơ quan tiến hành tố tụng, Cơ quan được giao nhiệm vụ tiến hành một số hoạt động tố tụng trong đấu tranh phòng, chống tội phạm, từ đó có biện pháp khắc phục, sửa chữa. Đồng thời, thông qua đó góp phần làm trong sạch bộ máy Cơ quan có thẩm quyền THTT, để các cơ quan này thực hiện tốt nhiệm vụ được giao trong TTHS. Bên cạnh đó, giám sát của $\mathrm{Co}$ quan dân cử, Đại biểu dân cử đối với hoạt động tố tụng hình sự cũng góp phần nâng cao chất lượng đội ngũ cán bộ của Viện kiểm sát, $\mathrm{Co}$ quan điều tra, Tòa án, Cơ quan thi hành án hình sự... Các hoạt động giám sát sẽ làm cho đội ngũ cán bộ tư pháp đặt chỉ tiêu công tác và mục đích thực hiện công vụ lên trên hết, tăng cường trách nhiệm công tác trong quá trình điều tra truy tố, xét xử vụ án hình sự. Bằng hoạt động giám sát, các chủ thể giám sát đưa ra được các biện pháp, cách thức, gợi ý... để các đối tượng chịu sự giám sát làm tốt hơn chức năng, nhiệm vụ của mình. Ngoài ra, thông qua giám sát, các quyết định của các cơ quan dân cử có thêm những căn cứ khoa học vững chắc, phù hợp với yêu cầu thực tế địa phương, đảm bảo tính khả thi của các quyết định, từ đó nâng cao hiệu lực, hiệu quả hoạt động của các cơ quan này trong thực tế.

iv) Giám sát của Cơ quan dân cử, Đại biểu dân cử đối với hoạt động TTHS góp phần bảo đảm quyền con người, quyền công dân trong quá trình giải quyết vụ án hình sự. Hoạt động tổ tụng hình sự là hoạt động có tính chất tác động mạnh mẽ đối với các quyền con người, quyền công dân như: quyền tự do về thân thể, quyền được bảo hộ về tính mạng, sức khỏe của con người... Các hoạt động bắt, tạm giữ, tạm giam, thi hành án hình sự đều ít nhiều ảnh hưởng tới các quyền này. Đồng thời hoạt động tố tụng hình sự cũng là hoạt động có khả năng sai sót cao. Bởi lẽ việc đi tìm chân lý, tìm nguyên nhân của sự việc đã xảy ra, tìm ra sự thật của vụ án không phải là câu chuyện đơn giản. Nhiều trường hợp hành vi của bị can rất khó để chứng minh. Do đó, hoạt động giám sát của Cơ quan dân cử, Đại biểu dân cử đối với hoạt động TTHS góp phần bảo đảm quyền con người, quyền công dân trong quá trình giải quyết vụ án hình sự.

v) Giám sát của Cơ quan dân cử, Đại biểu dân cử đối với hoạt động TTHS góp phần thực hiện cải cách tư pháp. Giám sát của các cơ quan dân cử đối với hoạt động tố tụng hình sự hướng tới thúc đẩy cải cách tư pháp ở Việt Nam hiện nay theo Nghị quyết số $08 / 2002 / N Q-T W$ của Bộ chính trị về một số vấn đề trọng tâm của công tác tư pháp trong thời gian tới; Nghị quyết 49/2005/NQ-TW của Bộ Chính trị về chiến lược cải cách tư pháp đển năm 2020 với mục tiêu xây dựng nền tư pháp trong sạch, vững mạnh. Trong Nghị quyết 49 đã nêu rõ "Đổi mới và tăng cường sự lãnh đạo của Đảng, phát huy vai trò giám sát của các cơ quan dân cử, của công luận và của nhân dân đối với hoạt động tư pháp". Như vậy hoạt động giám sát của các cơ quan dân cử là một mục tiêu là động lực của cải cách tư pháp, đồng thời là một trong những chức năng quan trọng của các cơ quan này. Kết quả giám sát là căn cứ, cơ sở để Đảng và Nhà nước vạch ra các chiến lược, kế hoạch tiếp theo trong công cuộc cải cách tư pháp.

4. Thực tế hoạt động giám sát của Cơ quan dân cử, Đại biểu dân cử cho thấy, bên cạnh những thành tựu còn có những hạn chế: Một là, hệ thống pháp luật điều chỉnh hoạt động giám sát chưa hoàn thiện, thiếu cụ thể, như: việc thu thập chứng cứ trong các giai đoạn giám sát 
chưa có những quy định pháp lý cụ thể dẫn đến khó khăn khi thực thi nhiệm vụ của đoàn giám sát. Hoạt động giám sát của Hội đồng nhân dân chưa có luật riêng điều chỉnh. Các quy định liên quan đến giám sát của Hội đồng nhân dân được thực hiện theo Hiến pháp, Luật Tổ chức Hội đồng nhân dân và Ủy ban nhân dân, Quy chế hoạt động của Hội đồng nhân dân, Nội quy các kỳ họp, Chương trình hoạt động toàn khoá... Do đó, các quy định về giám sát của Hội đồng nhân dân hiện đang nằm tản mạn trong nhiều văn bản khác nhau, còn chồng chéo, trùng lắp, không thuận lợi cho việc áp dụng, thực hiện pháp luật. Một số quy định về trình tự, thủ tục giám sát còn chưa rõ ràng, cụ thể và chưa bảo đảm tính thống nhất. Phạm vi giám sát của $\mathrm{Co}$ quan dân cử nói chung với hoạt động TTHS nói riêng còn quá rộng; Chưa phân định rõ về thẩm quyền, trách nhiệm của mỗi chủ thể giám sát đối với từng đối tượng chịu sự giám sát cũng như sự phối hợp giữa các chủ thể giám sát dẫn tới sự chồng chéo trong thực hiện. Một số quy định tính khả thi thấp, như quy định về việc HĐND bỏ phiếu tín nhiệm đối với người giữ chức vụ do HĐND bầu; Hai là, một số đại biểu Quốc hội, Đại biểu Hội đồng nhân dân trình độ và năng lực giám sát còn chưa đáp ứng được yêu cầu. Theo quy định tại Điều 4 Luật tổ chức Quốc hội năm 2014: Hiệu quả hoạt động của Quốc hội được đảm bảo bằng hiệu quả của các kỳ họp của Quốc hội, hoạt động của UBTVQH, Hội đồng Dân tộc, Ủy ban của Quốc hội, đoàn đại biểu Quốc hội và các đại biểu Quốc hội. Như vậy, có thể thấy rằng, hiệu quả hoạt động giám sát của Quốc hội nói chung và đối với hoạt động tố tụng hình sự nói riêng, trước hết phụ thuộc vào hoạt động giám sát của các đại biểu Quốc hội, đòi hỏi họ phải có năng lực, phẩm chất, trách nhiệm để thực hiện nhiệm vụ giám sát. Ba là, các điều kiện vật chất, kinh phí phục vụ cho hoạt động giám sát còn chưa được bảo đảm. Muốn thực hiện được quyền giám sát, Quốc hội, Hội đồng nhân dân phải tiến hành các hoạt động xem xét, theo dõi, đi kiểm tra thực tế..., để làm được việc đó Quốc hội, Hội đồng nhân dân phải có những điều kiện cơ bản như: trụ sở làm việc, phương tiện giao thông và thông tin, có thư viện và bộ phận lưu trữ về các tài liệu giám sát của Quốc hội, Hội đồng nhân dân, trước hết là văn bản pháp quy của các cơ quan chịu sự giám sát của Quốc hội, Hội đồng nhân dân.

5. Tăng cường hiệu quả giám sát của các cơ quan dân cử, đại biểu dân cử đối với hoạt động tố tụng hình sự hiện nay ở Việt Nam là đòi hỏi tất yếu, xuất phát từ những yêu cầu sau đây:

a. Xuất phát từ yêu cầu đổi mới công tác giám sát của các cơ quan dân cử đối với hoạt động tố tụng hình sự theo yêu cầu xây dựng nhà nước pháp quyền của nhân dân, do nhân dân, vì nhân dân. Nghị quyết số 49-NQ/TW ngày 02 tháng 06 năm 2005 của Bộ Chính trị đã chỉ rõ: "Đổi mới, nâng cao chất lượng chất vấn và trả lời chất vấn đối với hoạt động của các cơ quan tư pháp tại các kỳ họp của Quốc hội, hội đồng nhân dân. Quốc hội và Hội đồng nhân dân nên có nghị quyết riêng về hoạt động tư pháp sau khi nghe báo cáo và trả lời chất vấn. Tăng cường và nâng cao hiệu quả, hiệu lực giám sát việc chấp hành pháp luật của các cơ quan tư pháp, đặc biệt là của lãnh đạo các cơ quan tư pháp. Thành lập Ủy ban tư pháp của Quốc hội để giúp Quốc hội thực hiện nhiệm vụ giám sát hoạt động tư pháp, trọng tâm là việc bắt, giam giữ, truy tố, xét xử ";

b. Xuất phát từ yêu cầu nâng cao hiệu quả hoạt động giám sát của các cơ quan dân cử đối với hoạt động tố tụng hình sự. Thực tế khách quan trong hoạt động giám sát của các cơ quan dân cử đối với hoạt động tố tụng hình sự đòi hỏi các đại biểu dân cử phải có tri thức về ngành luật thuộc lĩnh vực mình giám sát (luật hình sự, luật dân sự, luật tố tụng hình sự, luật tố tụng dân sự...) phải am hiểu cơ cấu và tổ chức của các cơ quan xét xử của TAND, VKSND. Thiếu tri thức này, hoạt động của đại biểu sẽ không có hiệu lực, không góp phần tích cực cho hoạt động giám sát của Quốc hội đối với hoạt động tố tụng hình sự: Đặc biệt là về hoạt động giám sát các hoạt động tố tụng hình sự. Rõ ràng là hoạt động giám sát đòi hỏi đại biểu dân cử không chỉ am hiểu về luật nội dung, luật hình thức mà còn đòi hỏi đại biểu phải hiểu biết công việc của thẩm phán và hoạt động của hội thẩm 
nhân dân cộng thêm thực tiễn - môi trường xã hội phát sinh tội phạm. Mặc dù đã có nhiều cố gắng, song nhìn chung công tác giám sát của các cơ quan dân cử đối với hoạt động tố tụng hình sự vẫn chưa đáp ứng được yêu cầu đề ra. Để nâng cao hiệu lực hoạt động giám sát của cơ quan dân cử đối với hoạt động tố tụng hình sự cần giải quyết tốt các khiếm khuyết trên đây để từ đó đáp ứng các yêu cầu cụ thể;

c. Xuất phát từ yêu cầu hội nhập quốc tế. Trong quá trình hội nhập quốc tế hiện nay đòi hỏi những thay đổi quy mô hình trong tổ chức và hoạt động của bộ máy nhà nước. Hiện nay nhà nước ta đang tiếp tục ký kết gia nhập các điều ước quốc tế trong các lĩnh vực kinh tế, thương mại, đầu tư, tín dụng quốc tế, sở hữu trí tuệ, thuế quan, bảo vệ môi trường... Đồng thời, đẩy mạnh việc rà soát, sửa đổi, bổ sung hoặc ban hành các văn bản quy phạm pháp luật để phù hợp với thông lệ quốc tế và các điều ước quốc tế mà Việt Nam là thành viên. Do đó, nâng cao chất lượng và hiệu lực hoạt động của các cơ quan dân cử, nâng cao hiệu quả hoạt động giám sát của các cơ quan dân cử đối với hoạt động tố tụng hình sự chính là nhằm đáp ứng các đòi hỏi khách quan nói trên.

Đòi hỏi, yêu cầu nêu trên đặt ra những vấn đề cần tiếp tục nghiên cứu hoàn thiện pháp luật, nâng cao hiệu quả giám sát của Cơ quan dân cử, Đại biểu dân cử đối với hoạt động TTHS, đó là:

Thư nhất, thu hẹp phạm vi, hình thức giám sát của Cơ quan dân cử, Đại biểu dân cử đối với hoạt động TTHS. Theo qui định hiện hành thì phạm vi và hình thức giám sát quá rộng với nhiều chủ thể, chưa phân định rõ về thẩm quyền, trách nhiệm của mỗi chủ thể với từng đối tượng chịu sự giám sát cũng như sự phối hợp giữa các chủ thể giám sát dẫn tới sự chồng chéo, kém hiệu quả trong thực hiện. Một nghiên cứu gần đây đã chỉ ra "cần thu hẹp phạm vi giám sát của Quốc hội, HĐND, trước hết là thu hẹp trên thực tế, về lâu dài cần sửa đổi Hiến pháp và các luật có liên quan"[8] . Theo đó, Quốc hội, Đại biểu Quốc hội chỉ giám sát hoạt động TTHS của các cơ quan tư pháp Trung ương còn hoạt động TTHS của các cơ quan tư pháp địa phương thuộc thẩm quyền giám sát của Hội đồng nhân dân, đại biểu Hội đồng nhân dân.

Thư hai, xây dựng Luật về hoạt động giám sát của HĐND cấp tỉnh, huyện, xã, đảm bảo cho "HĐND giám sát việc tuân theo Hiến pháp và pháp luật ở địa phương và việc thực hiện nghị quyết của HĐND" theo quy định tại Hiến pháp năm 2013. Quy định chặt chẽ trình tự, thủ tục, trách nhiệm và các chế tài giám sát, xử lý sau giám sát góp phần nâng cao chất lượng, hiệu quả hoạt động giám sát của HĐND. Trong trường hợp chưa ban hành Luật về hoạt động giám sát của $\mathrm{HĐND,} \mathrm{đề} \mathrm{nghị} \mathrm{Ủy} \mathrm{ban} \mathrm{thường} \mathrm{vụ}$ Quốc hội có văn bản hướng dẫn cụ thể các quy trình, thủ tục, chế tài sau giám sát, tạo hành lang pháp lý để HĐND nâng cao hiệu quả giám sát. Ban hành văn bản quy định việc các cơ quan được giám sát phải báo cáo kết quả thực hiện những kiến nghị, đề xuất của Đoàn giám sát hoặc thành lập các Đoàn giám sát việc thực hiện kiến nghị của Thường trực HĐND, các ban HĐND theo từng lĩnh vực được giao. Đồng thời, khắc phục những quy định còn bất cập trong quy chế hoạt động của HĐND như: trách nhiệm gửi báo cáo của các cơ quan đến các ban của HĐND, tăng thêm thời gian đối với Thường trực HĐND khi xem xét các báo cáo; không quy định "cứng" thời gian trả lời chất vấn; chế tài xử lý "hậu chất vấn"... Trong nội dung của Luật Giám sát cần lưu ý một số nội dung sau: Quy định rõ chế tài đối với tổ chức, cá nhân không thực hiện, thực hiện không đúng các kiến nghị, kết luận sau giám sát; Trưởng đoàn giám sát có quyền đình chỉ hoạt động của tổ chức, cá nhân nếu vi phạm pháp luật hoặc thực hiện sai nghị quyết của HĐND. Đây là vấn đề quan trọng thể hiện vai trò và hiệu quả của hoạt động giám sát, thể hiện quyền lực nhà nước của HĐND trong phạm vi pháp luật cho phép; Luật Giám sát $\mathrm{HĐND}$ cần quy định rõ những hình thức giám sát, trong đó nên quy định hình thức giám sát lại nhằm kiểm tra việc thực hiện theo kiến nghị, kết luận của đối tượng bị giám sát chứ không phải chỉ là hoạt động báo cáo bằng văn bản mang tính hình thức như hiện nay. Nếu qua hoạt động giám sát lại mà thấy đối tượng bị giám sát không thực hiện hoặc thực hiện không 
đúng theo kết luận, kiến nghị của mình thì sẽ bị áp dụng các biện pháp chế tài nghiêm khắc tùy theo tính chất và mức độ vi phạm; Phân định rõ thẩm quyền, chức năng, nhiệm vụ giữa hoạt động giám sát của $\mathrm{HĐND}$ với hoạt động thanh tra, kiểm tra của các cơ quan nhà nước khác như: UBND, TAND, VKSND; Phân định rõ thẩm quyền, chức năng hoạt động giám sát của các Ban HĐND tỉnh với hoạt động giám sát của Thường trực HĐND tỉnh nhằm tránh tình trạng bỏ sót, trùng lặp trong hoạt động giám sát; Xây dựng hệ thống các tiêu chí đánh giá trong hoạt động giám sát là chuẩn mực chung thống nhất để đánh giá hiệu quả giám sát đối với từng Ban trong từng kỳ họp, trong từng năm và cả nhiệm kỳ; Luật cần quy định rõ về nhiệm vụ cụ thể của từng Ban trong hoạt động của mình, chứ không chỉ quy định nhiệm vụ chung của các Ban như hiện nay. Nếu trong Luật mà quy định cụ thể như vậy thì tính pháp lý sẽ cao hơn, việc tổ chức thực hiện cũng được đảm bảo tốt hơn và cũng tạo điều kiện thuận lợi cho địa phương trong quá trình thực hiện giá trị pháp lý của văn bản luật.

Thú $b a$, hoàn thiện các quy định pháp luật về việc bỏ phiếu tín nhiệm đối với các chức danh do HĐND cùng cấp bầu. Theo đó, việc bỏ phiếu tín nhiệm không nên chỉ xuất phát từ đề nghị của Ủy ban Mặt trận Tổ quốc Việt Nam cấp tỉnh và $1 / 3$ số đại biểu HĐND mà cần mở rộng quyền kiến nghị tới các chủ thể như: Thường trực HĐND chủ động trình HĐND, ban của HĐND kiến nghị, đồng thời giảm số đại biểu kiến nghị xuống còn $10 \%$ để đảm bảo tính thực tiễn của việc bỏ phiếu tín nhiệm. Cần quy định đây là hoạt động định kỳ, thường xuyên (hàng năm hoặc giữa nhiệm kỳ); làm rõ hơn nữa trình tự, thủ tục bỏ phiếu tín nhiệm, đặc biệt là những vấn đề liên quan đến trước và sau hoạt động bỏ phiếu tín nhiệm. Nên quy định HĐND bỏ phiếu "bất tín nhiệm" đối với các chức danh do HĐND bầu trong trường hợp có vi phạm pháp luật, đạo đức; còn trường hợp trách nhiệm chính trị, năng lực điều hành, hiệu quả trong thực thi nhiệm vụ yếu kém sẽ được lấy phiếu tín nhiệm theo quy định về lấy phiểu tín nhiệm đối với các chức danh do Quốc hội,
HĐND bầu hoặc phê chuẩn. Bên cạnh đó, đổi mới phương pháp điều hành các phiên chất vấn, tạo không khí cởi mở, tùy theo vấn đề chất vấn mà bố trí thời gian phù hợp, tăng cường hoạt động chất vấn giữa hai kỳ họp. Xem xét quy định hình thức chất vấn giữa hai kỳ họp tại Thường trực HĐND và do HĐND chủ trì là hoạt động thường xuyên của HĐND cấp tỉnh. Hoàn thiện các quy định pháp luật về việc xem xét các văn bản quy phạm pháp luật theo hướng nâng cao vai trò giám sát của HĐND cấp tỉnh, đặc biệt khi không còn hoạt động kiểm sát chung của VKSND. Để bảo đảm hiệu quả và hiệu lực giám sát của HĐND, cần quy định rõ trách nhiệm của các cơ quan, tổ chức trong việc thẩm định và thẩm tra văn bản pháp luật, đổi mới cơ chế xem xét và đề nghị HĐND bãi bỏ văn bản sai trái; bổ sung vai trò của TAND trong việc giám sát, xử lý văn bản pháp luật sai trái.

Thứ tux, nâng cao năng lực của các chủ thể thực hiện chức năng giám sát hoạt động tố tụng hình sự. Để nâng cao hiệu quả hoạt động giám sát của các cơ quan dân cử đối với hoạt động tố tụng hình sự thì phải nâng cao năng lực của đại biểu các cơ quan dân cử. Để bầu được những đại biểu có phẩm chất, có năng lực, trình độ, trước tiên cuộc bầu cử đại biểu dân cử các cấp nói chung và đại biểu HĐND tỉnh nói riêng phải được tổ chức chặt chẽ, theo quy định của pháp luật. Sau khi bầu được các đại biểu đảm bảo tiêu chuẩn, cơ cấu, họ phải được thường xuyên bồi dưỡng, tập huấn về nghiệp vụ, kiến thức quản lý nhà nước các văn bản liên quan đến hoạt động của các cơ quan dân cử và đại biểu dân cử; phải xây dựng quy chế hoạt động cho đại biểu. Đồng thời, phải có chế độ công tác phí, sinh hoạt phí... cũng như được sử dụng quỹ thời gian hợp lý để làm nhiệm vụ đại biểu... Trong quá trình hoạt động, những đại biểu tích cực cần được khen thưởng, động viên kịp thời. Cần tổ chức các hội nghị tập huấn nâng cao năng lực cho đại biểu dân cử với sự tham gia của các tỉnh qua đó cùng học tập để rút kinh nghiệm. Văn kiện Đại hội đại biểu toàn quốc lần thứ IX của Đảng tiếp tục xác định yêu cầu: "Hoàn thiện những quy định về bầu cử, ứng cử, 
về tiêu chuẩn cơ cấu của các Đại biểu Quốc hội và HĐND trên cơ sở phát huy dân chủ". Như vậy cần nâng cao chất lượng đại biểu dân cử cấp tỉnh theo hướng kết hợp tốt giữa yêu cầu về tiêu chuẩn và cơ cấu đại biểu, trong đó chú trọng tới chất lượng đại biểu, đảm bảo tính đại diện thực sự, đại biểu phải là những người tiêu biểu cho lĩnh vực hoạt động, ngành, giới, tầng lớp nhân dân, độ tuổi. Đại biểu dân cử là yếu tố quyết định bảo đảm hoạt động của dân cử trong đó có hoạt động giám sát tố tụng hình sự./.

\section{Tài liệu tham khảo}

[1] Nguyễn Đăng Dung, Hệ thống tòa án Việt Nam trong điều kiện xây dựng nhà nước pháp quyền, Nhà xuất bản ĐHQG, Hà Nội, năm 2010, tr41

[2] Nguyễn Sỹ Dũng - PGS.TS Vũ Công Giao, Hoạt động giám sát của cơ quan dân cử ở Việt Nam vấn đề và giải pháp, Nhà xuất bản Hồng Đức, Hà Nội, năm 2015, tr29.
[3] Nguyễn Đăng Dung, Nội dung các qui định về Quốc hội trong Hiến pháp 2013, trong sách “ Bình luận khoa học Hiến pháp nước CHXHCN Việt Nam năm 2013", Nhà xuất bản Lao động, Hà Nội, năm 2014, tr.171.

[4] Nguyễn Hòa Bình, Những nội dung mới trong Bộ luật tố tụng hình sự 2015, Nhà XB CTQG, Hà Nội, Năm 2016, tr.38.

[5] Lê Hữu Thể, Những vấn đề lý luận và thực tiễn cấp bách của việc đổi mới thủ tục tố tụng hình sự đáp ứng yêu cầu cải cách tư pháp, Nhà $\mathrm{XB}$ CTQG,Hà Nội, năm 2013,tr.512.

[6] Nguyễn Hòa Bình, những nội dung mới trong Bộ luật tố tụng hình sự năm 2015, nhà XB chính trị Quốc gia. Hà Nội, năm 2016, tr.38.

[7] Đảng Cộng sản Việt Nam (1986), Văn kiện Đại hội Đảng lần thứ VI, Hà Nội.

[8] Nguyễn Sỹ Dũng - PGS.TS Vũ Công Giao, Hoạt động giám sát của cơ quan dân cử ở Việt Nam vấn đề và giải pháp, Nhà xuất bản Hồng Đức, Hà Nội, năm 2015, tr.173.

\title{
The Supervision of Elective Office in Criminal Procedure
}

\author{
Nguyen Ngoc Chi ${ }^{1}$, Ha Thi Phuong Bac ${ }^{2}$ \\ ${ }^{l}$ VNU School of Law, 144 Xuan Thuy, Cau Giay, Hanoi, Vietnam \\ ${ }^{2}$ Ha Hoa District People's Committee, Phu Tho, Vietnam
}

\begin{abstract}
The supervisory mechanism of the Elective Office and the Elected Deputies is constituted based on the principle of inspection and supervision in criminal proceedings stipulated in Article 33, Criminal Procedure Code 2015. This monitoring mechanism well developes the Elective Office's role of overseeing criminal proceedings. In addition, it helps limit power abuse from the Competent authorities and Competent persons in conducting criminal proceedings. Furthermore, the mechanism can timely detect violations and instantly require those involved offices, agencies, organizations and individuals to overcome the issues. Nevertheless, that the de facto supervision of the Elective Office in criminal proceedings still encounters problems and limitations results in unsatisfactory litigious quality: violation of human rights and civil rights still remains, state benefits and legal order are not fully guaranteed, justice is not duly respected. To overcome these shorcomings, the article recommends solutions to surmount the existing bounds and difficulties for the Elective Office and the Elected Deputies in supervising criminal procedure proceedings.
\end{abstract}

Keywords: Supervision, Congress, People's Assembly, Criminal procedure, the Elective Office, the Elected Deputies. 